\title{
Characterization and Hydrogen Storage of Surface-Modified Multiwalled Carbon Nanotubes for Fuel Cell Application
}

\author{
Kuen-Song Lin, Yao-Jen Mai, Shin-Rung Li, Chia-Wei Shu, and Chieh-Hung Wang \\ Department of Chemical Engineering and Materials Science and the Fuel Cell Center, Yuan Ze University, Chungli 320, Taiwan \\ Correspondence should be addressed to Kuen-Song Lin, kslin@saturn.yzu.edu.tw
}

Received 2 July 2012; Accepted 23 August 2012

Academic Editor: Renzhi Ma

Copyright $\odot 2012$ Kuen-Song Lin et al. This is an open access article distributed under the Creative Commons Attribution License, which permits unrestricted use, distribution, and reproduction in any medium, provided the original work is properly cited.

\begin{abstract}
The synthesis, identification, and $\mathrm{H}_{2}$ storage of multiwalled carbon nanotubes (MWCNTs) have been investigated in the present work. MWCNTs were produced from the catalytic-assembly solvent (benzene)-thermal (solvothermal) route. $\mathrm{Reduction}$ of $\mathrm{C}_{6} \mathrm{Cl}_{6}$ with metallic potassium was carried out in the presence of $\mathrm{Co} / \mathrm{Ni}$ catalyst precursors at $503-623 \mathrm{~K}$ for $12 \mathrm{~h}$. XRD patterns indicated that the abstraction of $\mathrm{Cl}$ from hexachlorobenzene and the formation of $\mathrm{KCl}$ precipitates were involved in the early stage of the synthesis process of MWCNTs. This result offers further explanation for the formation of MWCNT structure and yield using the solvothermal route depending on the $\mathrm{Co} / \mathrm{Ni}$ catalyst precursors. The diameter of MWCNTs ranged between $30 \mathrm{and} 100 \mathrm{~nm}$ and the $\mathrm{H}_{2}$ storage capacity of MWCNTs improved when 2.7-3.8 wt $\%$ Pd or $\mathrm{NaAlH}_{4}$ were doped. The XANES/EXAFS spectra revealed that the $\mathrm{Co} / \mathrm{Ni}$ catalyst precursors of the MWCNT synthesis were in metallic form and Pd atoms possessed a Pd-Pd bond distance of $2.78 \AA$ with a coordination number of 9.08 . $\mathrm{Ti}^{-\mathrm{NaAlH}_{4}}$ or Pd nanoparticles were dispersed on MWCNTs and facilitated to improve the $\mathrm{H}_{2}$ storage capacity significantly with the surface modification process.
\end{abstract}

\section{Introduction}

Carbon nanotubes (CNTs) have been predicted to possess novel mechanical and unique electrical properties due to their regular, periodic structure and quantum size [1-4]. The applications for CNTs have enormous potentials such as novel nanoscale electronic devices, tips for scanning probe microscopy, hydrogen storage media, reinforcing materials for carbon matrix composites, and catalyst supports [35]. MWCNTs have earned intensive interest in the past decade because of their role in the emerging environmental and energy-related applications. The synthesis of metalcatalyzed CNTs has been pursued by a variety of methods that included chemical vapor deposition (CVD), laser, or arc process [6-12]. However, these methods are associated with the formation of many undesired by products and low yields, and many other separation challenges [13-17]. In addition, neither method is readily scalable for bulk commercial production [18-20]. Conversely, a low-cost, mass-producible, effective, and novel benzene-solvothermal route that involves the reduction of hexachlorobenzene $\left(\mathrm{C}_{6} \mathrm{Cl}_{6}\right)$ by metallic potassium $(\mathrm{K})$ in the presence of $\mathrm{Co} / \mathrm{Ni}$ catalyst precursors has been conducted in the present work $[7,9]$. However, the valency and fine structure of $\mathrm{Co}$ and $\mathrm{Ni}$ atoms also have not been well studied for the formation of CNTs. The concurrence of $\mathrm{Co} / \mathrm{Ni}$ metal nanoparticles nucleation leads to create a complex transient chemical environment and thus makes it difficult to study the inception and growth process of CNTs $[7,9]$. The $\mathrm{CoCl}_{2}{ }^{\bullet}$ and $\mathrm{NiCl}_{2}{ }^{\bullet}$ mixtures are reduced to $\mathrm{Co} / \mathrm{Ni}$ catalyzed particles by metallic potassium $(\mathrm{K})$, while $\mathrm{C}_{6} \mathrm{Cl}_{6}$ is also reduced by $\mathrm{K}$ through deleting chloride to form carbon clusters and $\mathrm{KCl}$ salts. Once the nucleation of CNTs from freshly reduced $\mathrm{Co} / \mathrm{Ni}$ metal particles has finished, the hexagonal carbon clusters diffuse to the growth sites through constant surface diffusion, then assemble into CNTs and cause the axial growth $[7,9]$. In addition, CNTs are known to possess significant catalytic activity via the $\pi$ and $\sigma$ bonds with $\mathrm{sp}^{2}$ hybridization state and that affects the potential ability for hydrogen adsorption $[21,22]$.

Complex metal hydrides, with the form $\mathrm{ABH}_{4}$ (where $\mathrm{A}$ is one of the alkali metals and B is a group III atom), have been widely studied in solution as proton acceptors for their ability to enhance $\mathrm{H}_{2}$ adsorption [23-30]. From some literature and reports, the increasing interest in $\mathrm{NaAlH}_{4}$ as 


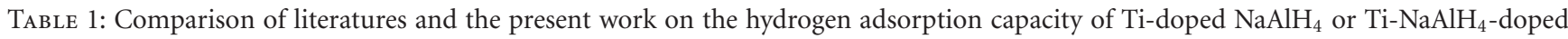
CNTs composites.

\begin{tabular}{|c|c|c|}
\hline Samples & Adsorption conditions & $\mathrm{H}_{2}$ adsorption capacity (wt $\left.\%\right)$ \\
\hline $\mathrm{NaAlH}_{4}+3 \mathrm{~mol} \% \mathrm{Ti}+1 \mathrm{~mol} \% \mathrm{Fe}[29]$ & $473 \mathrm{~K}$ and $1 \mathrm{~atm}$ & 4.3 \\
\hline $\mathrm{NaAlH}_{4}+4 \mathrm{~mol} \% \mathrm{Ti}[25]$ & $423 \mathrm{~K}$ and $1 \mathrm{~atm}$ & 3.5 \\
\hline $\mathrm{NaAlH}_{4}+2 \mathrm{~mol} \% \mathrm{Ti}+5 \mathrm{wt} \% \mathrm{Al}+10 \mathrm{wt} \% \mathrm{MWCNTs}$ (SWCNTs) $[54]$ & $473 \mathrm{~K}$ and $1 \mathrm{~atm}$ & $3.9(4.2)$ \\
\hline $\mathrm{NaAlH}_{4}+8 \mathrm{~mol} \%$ MWCNTs $[31]$ & $433 \mathrm{~K}$ and $1 \mathrm{~atm}$ & 4.2 \\
\hline $\mathrm{TiO}_{2}$-doped MWCNTs [51] & $298 \mathrm{~K}$ and $18 \mathrm{~atm}$ & 0.4 \\
\hline Ti-coated SWCNTs [55] (first-principle total-energy calculations) & $200-900 \mathrm{~K}$ and $1 \mathrm{~atm}$ & $5.0-8.0$ \\
\hline $4 \mathrm{wt} \% \mathrm{Ti}-\mathrm{NaAlH}_{4}+5 \mathrm{wt} \%$ MWCNTs (this work) & $425 \mathrm{~K}$ and $30 \mathrm{~atm}$ & 3.8 \\
\hline
\end{tabular}

a potential hydrogen storage material is arisen, particularly for being admixed with nonmetallic, lightweight, and highsurface-area CNTs [31-33]. Similarly, an alternative way of increasing the hydrogen adsorption capacities of MWCNTs is loading them with transition metals. Enormous progress has been made towards the development of metal-doped CNTs (Li, Ni, Pd, Fe, Pb, Pt, Al, Ti, V, or La) as a hydrogen gas storage material [34-51]. Nanoporous MWCNTs consisting of small transition metallic nanoparticles are exposed to the vicinity of pore volume and surface area and that can be a major concern for hydrogen storage abilities [19, 20, 23, 35, $41,45,46,52,53]$. Additionally, $\mathrm{Pd}, \mathrm{Pt}$, or $\mathrm{V}$ nanoparticle dispersions onto MWCNTs lead to hydrogen loadings up to $0.5 \mathrm{wt} \%[34,36,38-45,47,53,54]$. Rather et al. [46] reported that the hydrogen adsorption of $\mathrm{Pd}$-embedded CNTs possesses a maximum reversible hydrogen storage capacity of $0.18 \mathrm{wt} \%$ at $298 \mathrm{~K}$ and $1.6 \mathrm{MPa}$, which is nearly twice the storage capacity of pristine CNTs. According to Gundiah et al. [37] Pd-loaded MWCNTs showed enhanced hydrogen absorption kinetics on the storage system even though maximum adsorption was obtained of only $3.7 \mathrm{wt} \%$ at $300 \mathrm{~K}$. Yildirim and Ciraci [55] have reported that a single $\mathrm{Ti}$ atom adsorbed on single-walled CNTs can strongly bind to up to four hydrogen molecules using a computational study. In other words, single-walled CNTs decorated with Ti can strongly adsorb up to $8 \mathrm{wt} \%$ hydrogen. In addition, such available metals are recognized to play a role in the dissociation of hydrogen, followed by atomic hydrogen spillover, and finally adsorption onto MWCNTs. Using MWCNTs decorated by nanophase metal particles seems to be a promising method to improve hydrogen adsorption abilities. Based on the above principles, comparison of literature or reports on $\mathrm{Pd}$ or Ti-loaded MWCNTs and $\mathrm{NaAlH}_{4}$ composites is summarized in Table 1.

The XANES/EXAFS spectroscopy can be used to investigate the valency and fine structures of the complex metals (e.g., Ni, Co, Ti, or Pd) in as-synthesized MWCNTs. The XANES/EXAFS spectra offer a basic understanding of the oxidation states and fine structure of the metal-loaded MWCNTs for the characteristic nature of hydrogen adsorption. The XANES/EXAFS spectroscopy is also an excellent technique for characterizing the valency and local structure of $\mathrm{Pd} / \mathrm{Co} / \mathrm{Ni}$ metals in catalysts with short-range order [37, 56-58]. Thus, the main objective of the present study is to investigate the fine structure, oxidation states, or surface chemical modification of MWCNTs and $\mathrm{Pd} / \mathrm{Co} / \mathrm{Ni}$ atoms dispersed in the catalyst using HR-TEM, XRD, FE-SEM/EDS, and XANES/EXAFS spectroscopy. In addition, the adsorptive $\mathrm{H}_{2}$ storage capacity of as-synthesized MWCNTs, improved by adding Pd or Ti-NaAlH pressure microgravimetric balance.

\section{Experimental}

2.1. Starting Materials for MWCNTs Synthesis. The MWCNTs synthesis was conducted in a batch system. Benzene (100 mL) was placed into a $250 \mathrm{~mL}$ PTFE-lined 316 austenitic stainless steel autoclave. Then $15.0 \mathrm{~g} \mathrm{C}_{6} \mathrm{Cl}_{6}$ and $20.0 \mathrm{~g}$ metallic potassium $(\mathrm{K})$ were added under an argon-flowing glove box in order to prevent the metallic potassium species from oxidation. Subsequently, $70-80 \%$ of the volume of the autoclave was filled with $15 \mathrm{~mL}$ of benzene and $700 \mathrm{mg}$ of catalyst precursors. The catalyst precursor was prepared by dissolving $1.0 \mathrm{~g}$ of $\mathrm{CoCl}_{2} \cdot 6 \mathrm{H}_{2} \mathrm{O}$ and $\mathrm{NiCl}_{2} \cdot 6 \mathrm{H}_{2} \mathrm{O}$ mixture (mole ratio $\mathrm{Co} / \mathrm{Ni}=1$ ) in $100 \mathrm{~mL}$ of absolute ethanol, followed by drying at $353 \mathrm{~K}$ and calcining at $423 \mathrm{~K}$ in flowing air. All the chemicals used were high-purity (ACS grade). The sealed autoclave was heated in the furnace at 503$623 \mathrm{~K}$ for $8-12 \mathrm{~h}$, and then cooled to room temperature. The obtained samples were repeatedly and sequentially washed and filtrated with absolute ethanol, dilute acid, and deionized double-distilled water to remove the residual impurities, such as chlorides and the remaining catalyst, by using the ultrasonic method. The liquid residues were also further dried overnight to form $\mathrm{KCl}$ salt powders. Finally, the samples were vacuum-dried at $343-353 \mathrm{~K}$ for 6-10 h.

2.2. Surface Modification/Functionalization and Metals Doping. The surface modification process of as-synthesized MWCNTs was conducted by using a concentrated solution of $\mathrm{H}_{2} \mathrm{SO}_{4} / \mathrm{HNO}_{3}$ (ratio = 3) reflux for $1 \mathrm{~h}$ at $393 \mathrm{~K}$. The MWCNTs with a surface modification have lots of $\mathrm{COOH}$, $\mathrm{OH}$, or $\mathrm{NO}_{2}$ functional groups that possibly enhance the hydrogen adsorption abilities. Moreover, the well-dispersed surface-modified $5 \mathrm{wt} \%$ Pd-doped MWCNTs were prepared by adding $\mathrm{MWCNTs}$ into $\mathrm{PdCl}_{2(\mathrm{aq})}$ for well dispersion or impregnation and dried in alcohol solution at $323 \mathrm{~K}$. Finally, the PdO/MWCNTs were reduced to form the active 
Pd/MWCNTs with flowing hydrogen gases at 393-433 K for $6 \mathrm{~h}$ for the further measurement of hydrogen adsorption.

The two samples of $95 \mathrm{wt} \% \mathrm{Ti}-\mathrm{NaAlH}_{4}(4 \mathrm{wt} \% \mathrm{Ti})+$ $5 \mathrm{wt} \%$ MWCNTs and $95 \mathrm{wt} \% \mathrm{NaAlH}_{4}+5 \mathrm{wt} \%$ MWCNTs were mechanically admixed for the period of $30 \mathrm{~min}$ at milling speeds of 5,500 rpm under argon atmosphere by using a SPEX 8000 ball mill, respectively. A hardened steel crucible and six steel balls $12 \mathrm{~mm}$ in diameter were used for the milling. The ball to powder weight ratio was $12.5: 1$. The samples were then used for hydrogen adsorption capacity test and the microstructure characterization.

\subsection{Hydrogen Adsorption Capacity Measurement. Dihydro-} gen isotherms were measured gravimetrically at different temperatures using a method previously described by $\mathrm{Li}$ et al. [59]. A Cahn Thermax 500 microgravimetric balance with a sensitivity of $1 \mathrm{~g}$ was used to measure the changes in mass of MWCNT samples suspended within a glass enclosure under a certain atmosphere. A pressure sensor, with a range of 0 to $68 \mathrm{~atm}$ and sensitivity of $0.011 \mathrm{~atm}\left(\right.$ at $1,000^{\circ} \mathrm{C}$ ), was used to measure the hydrogen pressure in the chamber. MWCNT samples were outgassed overnight until a constant mass was attained; these varied from 0.2 to $2.0 \mathrm{~g}$. Prior to admittance of the analyte gas, the entire chamber and manifold were evacuated overnight. The system was purged at room temperature three times with the analyte gas and gases were passed through a molecular sieve trap immersed in liquid nitrogen to remove any condensable impurities and a two-step liquid nitrogen trap system was also conducted for the complete removal of moisture content in the flowing hydrogen gas ( $>99.999 \%$, of high purity) before being exposed to the samples. Pressures were measured with the range covering 1 to $30 \mathrm{~atm}$. Hydrogen was added incrementally, and data points were recorded when no further change in mass was observed. The dynamic and equilibrium hydrogen adsorption data were also taken at room temperature $(298 \mathrm{~K}$ ) to $425 \mathrm{~K}$ and different pressures. The adsorbed amount of hydrogen was calculated after the buoyancy correction. For the buoyancy correction $[60,61]$, the volume of the sample container and the samples were determined using a helium measurement assuming that helium adsorption at room temperature can be neglected.

2.4. Characterization and Identification. The average $\mathrm{Co} / \mathrm{Ni}$ metal contents in the catalyst precursor were evaluated by atomic absorption spectroscopy (AAS, GBC model 908) and induced coupled plasma/mass spectroscopy (ICP/MS, ELAN model 5000). Each calibration curve was generated with its corresponding standard metal solution at ten different concentrations and that generated the expected $\mathrm{Co} / \mathrm{Ni}$ metal concentrations in the catalyst. Then the concentration of $\mathrm{Co} / \mathrm{Ni}$ in the catalyst precursor was calculated. The morphologies of the samples were observed with Zeiss 10C transmission electron microscope (TEM) at $200 \mathrm{kV}$, and the microstructures of MWCNTs were measured with a JEOL 2010 high-resolution transmission electron microscope (HRTEM) also at $200 \mathrm{kV}$. Samples for the electron microscope were prepared by $1 \mathrm{~h}$ ultrasonic dispersion of $0.2 \mathrm{~g}$ of product with $50 \mathrm{~mL}$ of absolute ethanol in a $100 \mathrm{~mL}$ conical flask.
Then a drop of the solution was placed on a copper microgrid or carbon film and dried in air before observation. Further elemental microstructures of the MWCNTs were determined by FE-SEM/EDS (Hitachi, S-4700 Type II) with a resolution of $0.1 \mathrm{~nm}$. Structures of the MWCNTs or $\mathrm{Co} / \mathrm{Ni}$ precursors samples were measured by X-ray powder diffraction (XRD) scanned from 10 to $90^{\circ}(2 \theta)$ with a scan rate of $4^{\circ}(2 \theta)$ $\min ^{-1}$ with monochromatic $\mathrm{CuK}_{\alpha}$ radiation (MAC Science, MXP18) at $30 \mathrm{kV}$ and $20 \mathrm{~mA}$. The specific peak intensities and $2 \theta$ values recorded can be further identified by a computer database system (JCPDS). The surface area of the MWCNTs was measured by BET (Brunauer-EmmettTeller) nitrogen adsorption (Micromeritics ASAP 2010 Instrument). For the BET surface area measurements, the catalyst was scraped from the tube substrate and powdered so as to avoid any influence from the steel tube. Prior to measurement, all samples were degassed at $423 \mathrm{~K}$ for $1 \mathrm{~h}$. For the calculation of the BET surface areas, the relative pressure range $P / P_{0}$ of 0.05 to 0.2 was used. The pore radius distribution was determined by the Barrett, Joyner, and Halenda (BJH) method.

\subsection{XANES/EXAFS Measurement. The XANES/EXAFS} spectra were collected at $01 \mathrm{C} 1$ and the Wiggler $17 \mathrm{C} 1$ beamlines at the National Synchrotron Radiation Research Center (NSRRC) of Taiwan. The electron storage ring was operated with energy of $1.5 \mathrm{GeV}$ and a current of 100-200 mA. A Si(111) DCM was used for providing highly monochromatized photon beams with energies of 1 to $15 \mathrm{keV}$ and resolving power $(E / \Delta E)$ of up to 7,000 . Data were collected in fluorescence or transmission mode with a Lytle ionization detector [62] for Pd $(26,711 \mathrm{eV})$, Co $(7,709 \mathrm{eV})$, and $\mathrm{Ni}(8,333 \mathrm{eV}) \mathrm{K}$-edge experiments at room temperature. The photon energy was calibrated by characteristic preedge peaks in the absorption spectra of $\mathrm{Pd}, \mathrm{Co}$, and $\mathrm{Ni}$ foil standards. The raw absorption data in the region of 50 to $200 \mathrm{eV}$ below the edge position were fit to a straight line using the least-square algorithms [37, 46, 62]. The XANES extends to energy of the order of $50 \mathrm{eV}$ above the edge. The EXAFS function was derived from the raw absorption data through the pre- and post-edge background subtraction and then normalized with respect to the edge jump by using the program package AUTOBK. The $k^{2}$ - or $k^{3}$-weighted and EXAFS spectra were Fourier transformed to $R$ space over the range between 2.5 and $12.5 \AA^{-1}$. Local structural parameters such as the bond distance $R$, coordination number $N$, and Debye-Waller factor $\sigma$, for different coordination shells surrounding the absorbing atoms, were obtained through nonlinear least-square fitting routine. The EXAFS data were analyzed using the UWXAFS 3.0 program and FEFF 8.20 codes based on the crystallographic data of individual species [37, 56-58].

\section{Results and Discussion}

The MWCNTs were synthesized by $\mathrm{Co} / \mathrm{Ni}$ catalyst precursors with metallic $\mathrm{K}$ and then doping of palladium on the surface was investigated to understand the morphological behaviors. The HR-TEM micrographs shown in Figure 1 


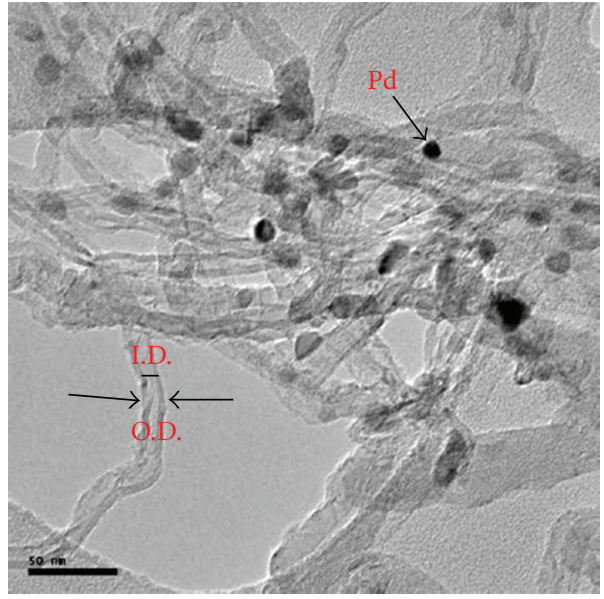

(a)

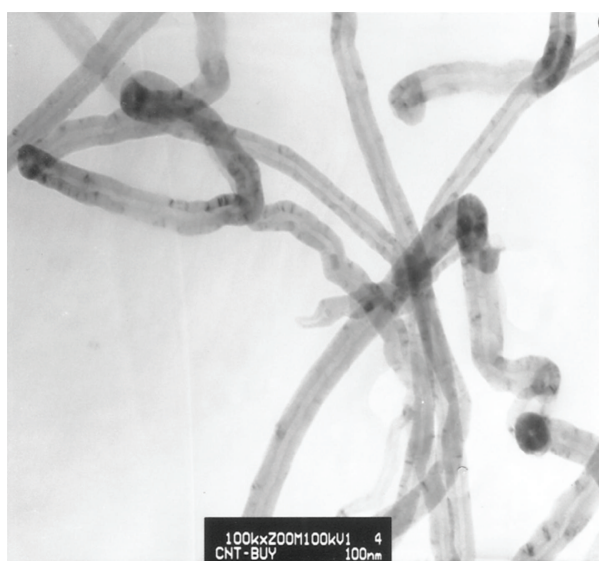

(c)

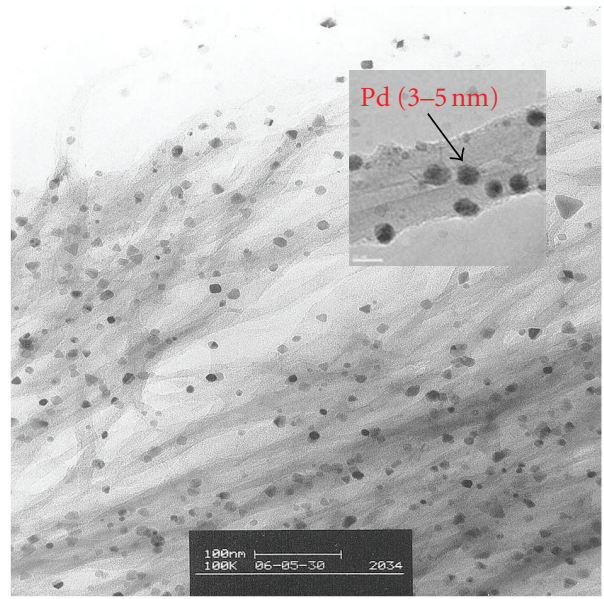

(b)

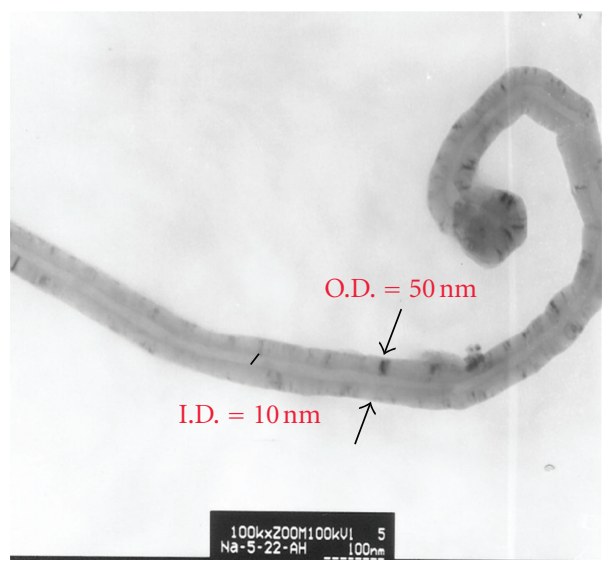

(d)

FIGURE 1: HR-TEM images of ( $a, b)$ well-dispersed Pd nanoparticles on the MWCNTs surfaces and (c, d) irregular-shaped of MWCNTs synthesized by $\mathrm{Co} / \mathrm{Ni}$ catalyst precursors with metallic $\mathrm{K}$ at $T=503-623 \mathrm{~K}$ for $12 \mathrm{~h}$.

were used to investigate the crystallinity and microstructures of the as-synthesized MWCNTs. As shown in Figure 1, the MWCNTs have an irregularly shaped structure with an average length of 1-500 $\mathrm{nm}$. Additionally, the inner and outer average diameters of the MWCNTs are around 20-40 and 45$100 \mathrm{~nm}$, respectively, and clearly visible in Figures $1(\mathrm{~b})-1(\mathrm{~d})$. The inner tube is subdivided by a single or multigraphite layer, which is formed by the surface diffusion of carbon cluster on the larger $\mathrm{Co} / \mathrm{Ni}$ catalytic nanoparticles $[17,46]$. In addition, palladium metals are uniformly distributed throughout the surface of MWCNTs (Figures 1(a)-1(b)), thus leading to the formation of the metallic particles consisting of 5 to $10 \mathrm{~nm}$ and representing the porous cavities $[17,52]$. The MWCNTs were attained with irregular shapes and shown in Figures 1(b)-1(d).

Pretreatment of MWCNTs was carried out with acid or ultrasonic purification and led to forming typically open ended nonamorphous carbon coating [52]. According to the energy dispersive spectrometer (EDS) analysis (Figure 2(a)), the K species are present in microcrystalline MWCNTs synthesized by $\mathrm{Co} / \mathrm{Ni}$ catalyst precursors. Figure 2 (b) revealed that $\mathrm{KCl}$ solid residues were formed in the MWCNTs washing liquids after drying overnight. Therefore, the postulated equation and reaction mechanism of the MWCNTs synthesis may be described as follow:

$$
\begin{aligned}
n \mathrm{C}_{6} \mathrm{Cl}_{6}+n \mathrm{~K} \longrightarrow & 6 n \mathrm{KCl}+\text { polyaromatic hydrocarbons } \\
& (+ \text { benzene at } 503-623 \mathrm{~K}) \\
\longrightarrow & \text { MWCNTs }(+\mathrm{Co} / \mathrm{Ni} \text { for } 8-12 \mathrm{~h}) .
\end{aligned}
$$

The structure of the MWCNTs compound was confirmed by structural refinement of X-ray diffraction patterns shown in Figure 3. The intensive peaks appearing at small $2 \theta$ angles are characteristics of porous materials which possess numerous pores or cavities. In Figure 3, the XRD patterns indicate that the abstraction of $\mathrm{Cl}$ from hexachlorobenzene and the formation of $\mathrm{KCl}$ precipitates were involved in the early stage of the synthesis process of MWCNTs. Most of the $\mathrm{KCl}$ from the MWCNTs sample can be removed by washing with D.I. water (Figures 3(b) and 3(c)). $\mathrm{KCl}$ was the main component and over $95 \%$ of $\mathrm{K}^{+}$cations were transformed 


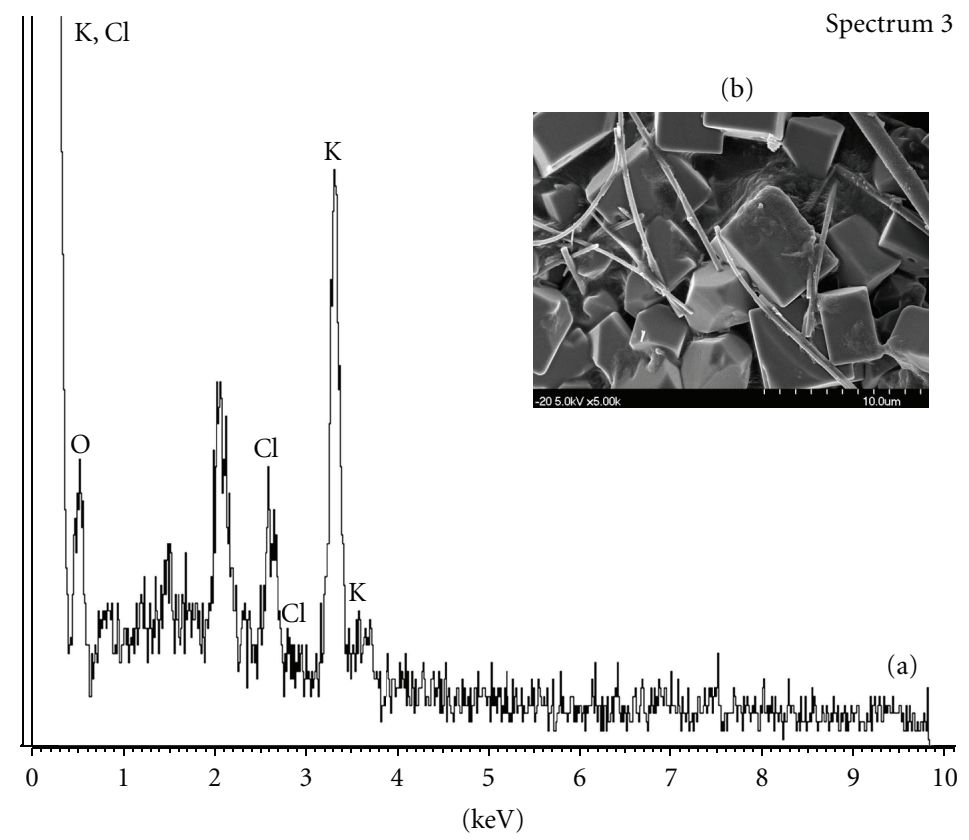

Full scale $85 \mathrm{cts}$

Cursor: $-0.004 \mathrm{keV}$ (4619cts)

FIGURE 2: FE-SEM/EDS measurement of (a) the surface of MWCNTs synthesized using Co/Ni catalyst precursors with metallic K at $T$ = $503-623 \mathrm{~K}$ for $12 \mathrm{~h}$ and (b) $\mathrm{KCl}$ solid residues formed after drying overnight in the washing liquids of MWCNTs purification process.

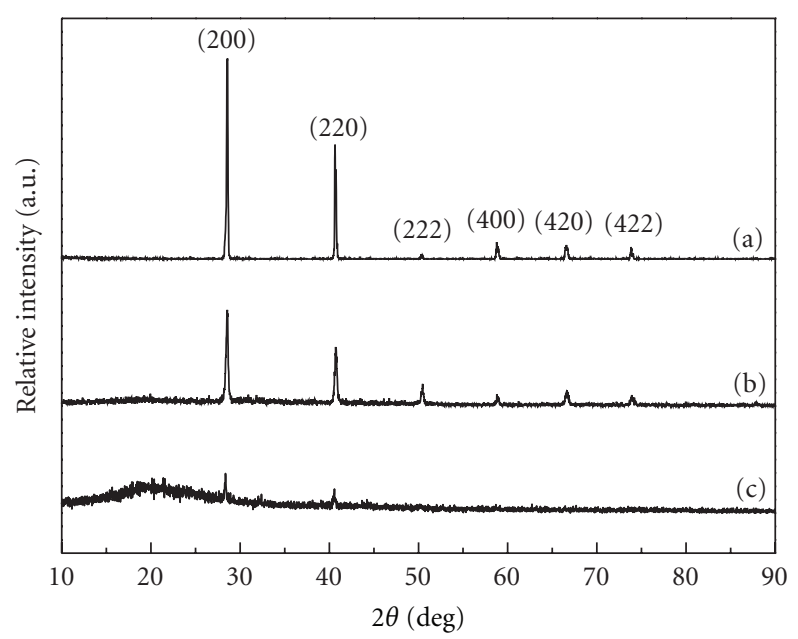

FIGURE 3: XRD patterns of (a) $\mathrm{KCl}$ standard, (b) unwashed MWCNTs with $\mathrm{KCl}$ crystals, and (c) washed MWCNTs with $\mathrm{KCl}$ contaminants synthesized by $\mathrm{Co} / \mathrm{Ni}$ catalyst precursors at $T=503-$ $623 \mathrm{~K}$ for $12 \mathrm{~h}$.

into $\mathrm{KCl}$ in the synthesis process of the MWCNTs using $\mathrm{Co} / \mathrm{Ni}$ catalyst precursors at $T=503-623 \mathrm{~K}$ for $8-12 \mathrm{~h}$.

Furthermore, the XRD patterns of $\mathrm{Pd}$ and $\mathrm{Ti}-\mathrm{NaAlH}_{4}-$ doped MWCNTs indicate that the metallic particles have a crystalline structure (Figure 4) and therefore could enhance the surface area with their higher roughness as well as hydrogen-adsorption ability of the MWCNTs. According to FE-SEM, the dispersion of metallic Pd on the surface of

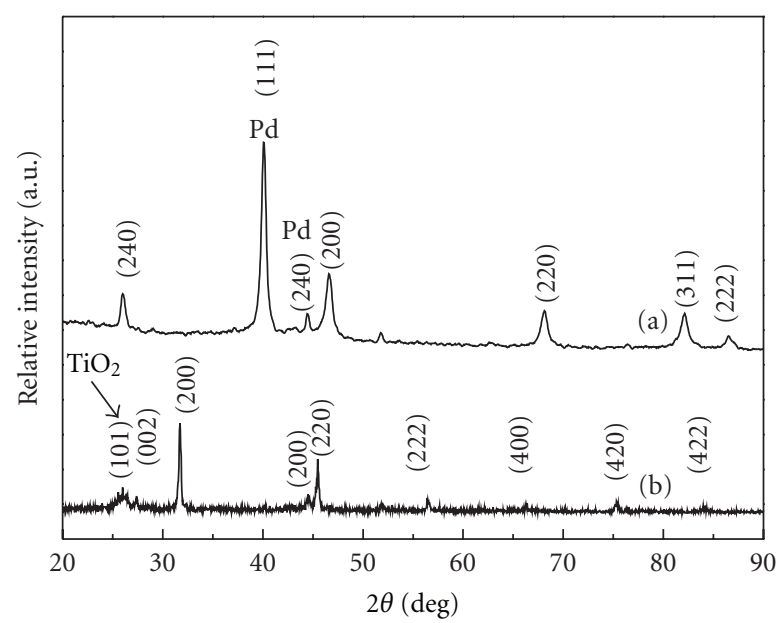

FIgure 4: XRD patterns of (a) $5 \mathrm{wt} \%$ Pd-doped and (b) $4 \mathrm{wt} \%$ Ti$\mathrm{NaAlH}_{4}$-doped MWCNTs synthesized by $\mathrm{Co} / \mathrm{Ni}$ catalyst precursors at $T=503-623 \mathrm{~K}$ for $12 \mathrm{~h}$.

MWCNTs apparently facilitated similar consequences. The XRD patterns of $\mathrm{Pd}$ (Figure 4(a)) exhibit characteristic sharp peaks at $2 \theta=40.12$ and $46.77^{\circ}$, which are consistent with $5-10 \mathrm{~nm}$ particle size. As shown in Figure 4(b), the peak at $2 \theta=26.3^{\circ}$ of $\mathrm{Ti}-\mathrm{NaAlH}_{4}$-doped sample also indicates that the largely crystalline structure attributes the particle size as $80-120 \mathrm{~nm}[28,51,55,63]$. This particle size was roughly calculated using Scherrer's equation (with Warren's 
TABle 2: Fine structural parameters of $\mathrm{Ni}, \mathrm{Co}$, $\mathrm{Pd}$ or $\mathrm{PdCl}_{2}$ powder standard, catalyst precursor residues, and non-surface- or surfacemodified $5 \mathrm{wt} \%$ MWCNTs with hydrogen reduction analyzed using EXAFS technique.

\begin{tabular}{|c|c|c|c|c|}
\hline Samples & Shell & $\mathrm{CN}^{\mathrm{a}}( \pm 0.05)$ & $R^{\mathrm{b}}( \pm 0.05 \AA)$ & $\sigma^{2}\left(\AA^{2}\right)^{\mathrm{c}}$ \\
\hline Nickel powder standard & $\mathrm{Ni}-\mathrm{Ni}$ & 3.01 & 2.43 & 0.0087 \\
\hline Catalyst precursor residue $(\mathrm{Ni})$ & $\mathrm{Ni}-\mathrm{Ni}$ & 2.92 & 2.48 & 0.0058 \\
\hline Cobalt powder standard & $\mathrm{Co}-\mathrm{Co}$ & 6.02 & 2.45 & 0.0046 \\
\hline Catalyst precursor residue (Co) & $\mathrm{Co}-\mathrm{Co}$ & 5.96 & 2.49 & 0.0067 \\
\hline Pd powder standard & $\mathrm{Pd}-\mathrm{Pd}$ & 9.21 & 2.76 & 0.0058 \\
\hline $\mathrm{PdCl}_{2}$ powder standard & $\mathrm{Pd}-\mathrm{Cl}$ & 2.13 & 2.25 & 0.0042 \\
\hline NHR 5 wt\% Pd-doped MWCNTs ${ }^{\mathrm{d}}$ & $\mathrm{Pd}-\mathrm{Pd}$ & 8.98 & 2.80 & 0.0112 \\
\hline HR 5 wt $\%$ Pd-doped MWCNTs ${ }^{\mathrm{e}}$ & Pd-Pd & 9.08 & 2.78 & 0.0093 \\
\hline
\end{tabular}

${ }^{a} \mathrm{CN}$ denotes "coordination number";

${ }^{\mathrm{b}} R$ denotes "bond distance";

c $\sigma$ denotes "Debye-Waller factor";

${ }^{\mathrm{d}}$ NHR $5 \mathrm{wt} \%$ Pd-doped MWCNTs denotes "as-synthesized non-surface-modified $5 \mathrm{wt} \%$ multiwalled carbon nanotubes reduced at $453 \mathrm{~K}$ under flowing hydrogen gas for $6 \mathrm{~h}$ ";

${ }^{\mathrm{e}} \mathrm{HR} 5 \mathrm{wt} \%$ Pd-doped MWCNTs denotes "as-synthesized surface-modified $5 \mathrm{wt} \%$ multiwalled carbon nanotubes reduced at $453 \mathrm{~K}$ under flowing hydrogen gas for $6 \mathrm{~h}$ ".

correction for instrumental broadening) applied at half the height of the maximum intensity diffraction peak.

Generally, the XANES/EXAFS spectroscopy can provide the information on the atomic arrangement of sorbents in terms of bond distance, coordination number, and kind of neighbors. Since the valency and fine structures of Co and $\mathrm{Ni}$ atoms used as the catalyzer precursor of the MWCNTs formation have not been well studied, XANES and EXAFS spectra may determine the catalytic redox mechanisms for the growth of MWCNTs. By using XANES spectra, all metallic Co or Ni species of the solid residues were found in the MWCNTs as shown in Figure 5(a). XANES or EXAFS data indicate that in the presence of metallic potassium the chlorides of $\mathrm{Co}$ and $\mathrm{Ni}$ were reduced to $\mathrm{Co} / \mathrm{Ni}$ catalyst particles. Simultaneously, hexachlorobenzene was also reduced by potassium through releasing chlorides to form carbon clusters and $\mathrm{KCl}$.

A high reliability of the EXAFS data fitting for Pd species in MWCNTs was obtained. The data were collected several times and standard deviation also calculated from the average spectra. Fourier transformation (FT) was performed on $k^{2}$ - or $k^{3}$-weighted oscillations over the range of $2.2-10 \AA^{-1}$. The radial structure function derived from the FT is shown in Figure 5(b) and Table 2. The EXAFS data of $\mathrm{Co} / \mathrm{Ni}$ precursor residues revealed that the nanophase metallic $\mathrm{Co}$ or $\mathrm{Ni}$ particles had a central Co (or Ni) atom with a coordination number of $2.92 \pm 0.05$ (or $5.96 \pm 0.05$ ) and a primarily $\mathrm{Co}-\mathrm{Co}$ bond distance of $2.49 \pm 0.05 \AA$ (or $2.48 \pm 0.05 \AA$ ). The coordination number for $\mathrm{Pd}$ powder is $9.21 \pm 0.05$ with a $\mathrm{Pd}-\mathrm{Cl}$ bond distance of $2.13 \pm 0.05 \AA$. Moreover, Pd-doped surfacemodified and nonmodified MWCNTs have the coordination numbers of 9.08 and $8.98 \pm 0.05$, respectively.

Hydrogen reduction occurs with the palladium particles on the central atom. These results obtained from XANES/EXAFS may offer further explanation of the yield and structure of MWCNTs formed using catalytic-assembly benzene-solvothermal route. However, the results combined with HR-TEM images (Figures 1(a) and 1(b)) may indicate that the $\mathrm{Co} / \mathrm{Ni}$ metal particles are responsible for the nucleation of the MWCNTs growth and belongs with some bending structures at close ends of the tubes. The concurrence of nucleation of the $\mathrm{Co} / \mathrm{Ni}$ metal nanoparticles and MWCNTs growth within a reactive hydrocarbon atmosphere (e.g., benzene) create a complex transient chemical environment, making it difficult to study the inception and growth processes in MWCNTs synthesis.

Nonspecific physical adsorption of the nonmodified and $5 \mathrm{wt} \%$ Pd-doped MWCNTs was carried out to measure the total surface area and pore size distribution as shown in Figure 6. The surface area and total pore volume were calculated according to the adsorption data summarized in Table 3. A large surface area was generally observed for Pd-doped MWCNTs with the surface-modified processes. Most of the microcrystalline structures of Pd on the MWCNTs were confirmed from the HR-TEM analysis (Figure 1) and that was helpful to increase the surface area and hydrogen adsorption capacity. The adsorptiondesorption isotherms exhibit a hysteresis behavior, indicating that the specimens were mainly mesoporous. Also, the type IV hysteresis isotherm was obtained and is represented in Figure 6. The adsorption hysteresis was observed in the region of a relative pressure $P / P_{0}$ above 0.8 . A comparison between the shapes of the two isotherms in the pressure range of $P / P_{0} \quad 0-0.9$ (Figures $6(\mathrm{a})$ and $6(\mathrm{~b})$ ) reveals a more pronounced hysteresis in the Pd-doped MWCNTs belonging with the surface modification. In addition, BET $\mathrm{N}_{2}$ adsorption for MWCNTs and Pd-doped MWCNTs were 79.4 and $114.2 \mathrm{~m}^{2} \mathrm{~g}^{-1}$ and pore volumes were 0.18 and $0.32 \mathrm{~cm}^{3} \mathrm{~g}^{-1}$, respectively. It also indicated that the resulting factor of surface enhancement depended on the surface modification of the Pd on the MWCNTs.

These results caused by the dispersion of the Pd on the MWCNTs surface were due to the surface modification using a concentrated solution of $\mathrm{H}_{2} \mathrm{SO}_{4} / \mathrm{HNO}_{3}($ ratio = 3) reflux for $1 \mathrm{~h}$ at $393 \mathrm{~K}$. In general, microporosity of the MWCNTs exposed with the increase of hydrogen reduction at $453 \mathrm{~K}$ under flowing hydrogen gas for $6 \mathrm{~h}$. According to Table 3, the BET surface area was increased notably with 

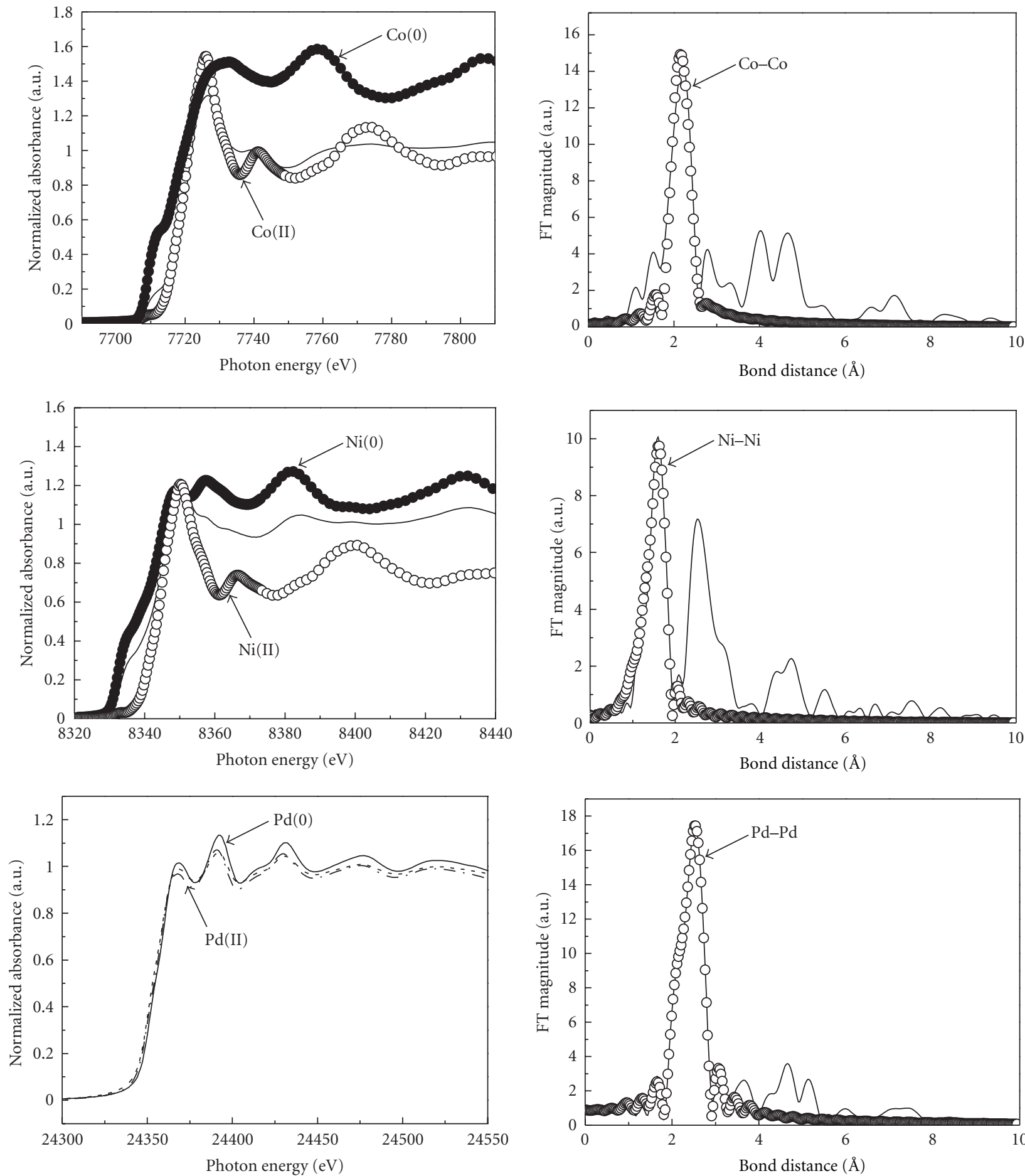

(a)

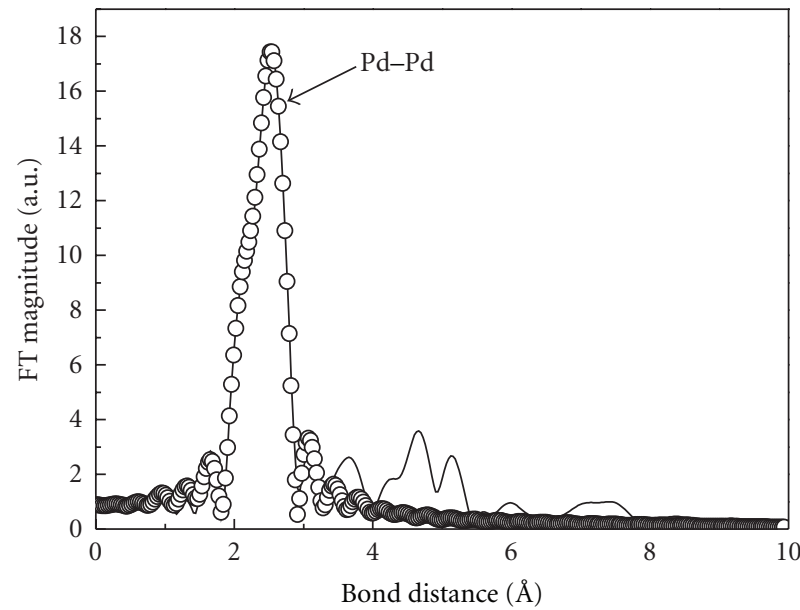

(b)

Figure 5: (a) XANES of Co/Ni precursor residue samples (solid lines) compared with $\mathrm{Co}(0, \mathrm{II}), \mathrm{Ni}(0, \mathrm{II})$, or $\mathrm{Pd}(0, \mathrm{II})$ standards and (b) Fourier transform (FT) of the metallic Co, Ni, or Pd K-edge EXAFS of the MWCNTs synthesized using Co/Ni catalyst precursors at $T=$ $603 \mathrm{~K}$ for $8-12 \mathrm{~h}$. The best fitting of EXAFS spectra are expressed by the dotted and circled lines.

hydrogen reduction on the nonmodified and $5 \mathrm{wt} \% \mathrm{Pd}-$ doped MWCNTs and was observed as 89.4 and $128.6 \mathrm{~m}^{2} \mathrm{~g}^{-1}$, where as the pore volumes were 0.24 and $0.84 \mathrm{~cm}^{3} \mathrm{~g}^{-1}$, respectively. Specific BET surface area of Pd-doped MWCNT sample started to increase due to the exposure of the nanophase Pd particles loaded on the surface of MWCNTs to hydrogen reduction, which might induce the microporosity and perfections in the carbon structures. 


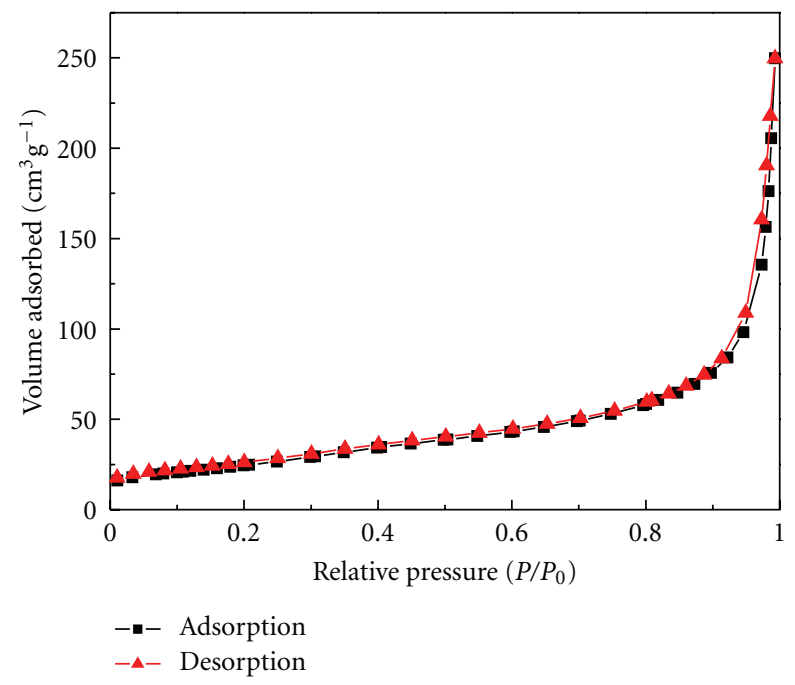

(a)

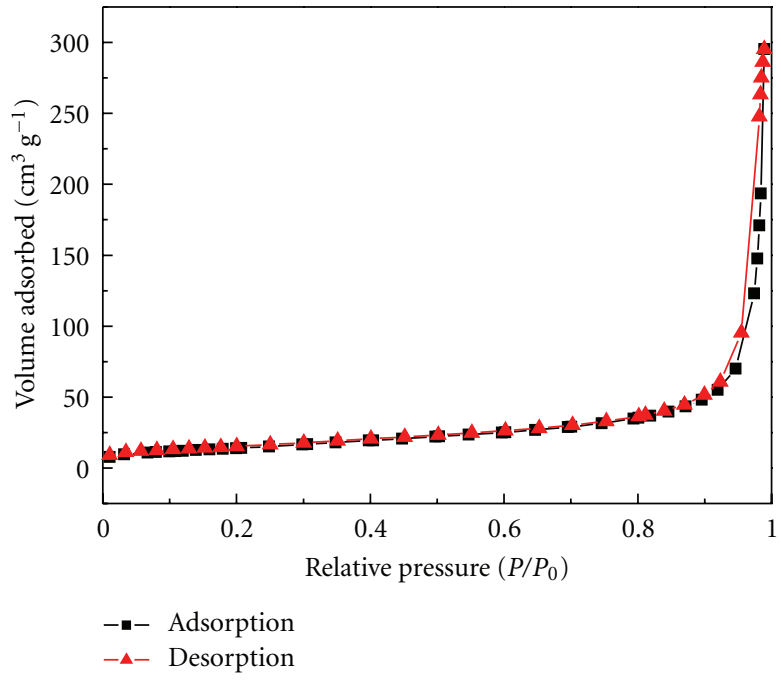

(b)

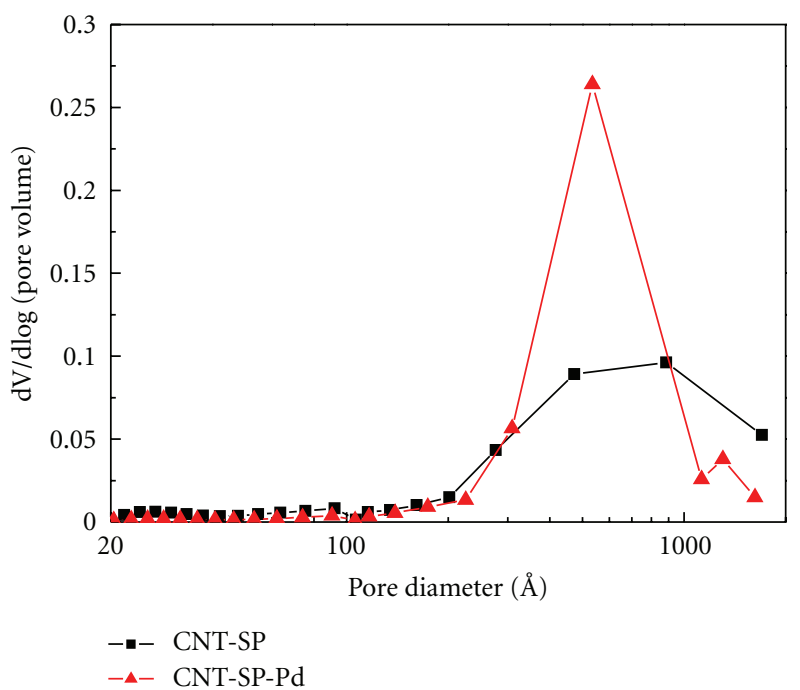

(c)

FIGURE 6: (a) Nitrogen adsorption/desorption isotherms of non-surface-modified 5 wt $\%$ Pd-doped MWCNTs and (b) surface-modified $5 \mathrm{wt} \%$ Pd-doped MWCNTs, and (c) pore size distributions of non- and surface-modified $5 \mathrm{wt} \%$ Pd-doped MWCNTs samples.

TABLE 3: Specific BET surface area and total pore volumes of nonsurface- or surface-modified MWCNTs and 5 wt $\%$ Pd-doped MWCNTs using $\mathrm{H}_{2} \mathrm{SO}_{4} / \mathrm{HNO}_{3}$ (ratio = 3) reflux for $1 \mathrm{~h}$ at $393 \mathrm{~K}$.

\begin{tabular}{lcc}
\hline Samples & BET surface area $\left(\mathrm{m}^{2} \mathrm{~g}^{-1}\right)$ & Total pore volume $\left(\mathrm{cm}^{3} \mathrm{~g}^{-1}\right)$ \\
\hline Non-surface-modified MWCNTs & 79.4 & 0.18 \\
Surface-modified MWCNTs & 114.2 & 0.32 \\
NHR 5 wt\% Pd-doped MWCNTs ${ }^{\mathrm{a}}$ & 89.4 & 0.24 \\
HR 5 wt\% Pd-doped MWCNTs & 128.6 & 0.38 \\
\hline
\end{tabular}

${ }^{\mathrm{a}} \mathrm{NHR} 5 \mathrm{wt} \% \mathrm{Pd}$-doped MWCNTs denotes "as-synthesized non-surface-modified $5 \mathrm{wt} \%$ multiwalled carbon nanotubes reduced at $453 \mathrm{~K}$ under flowing hydrogen gas for $6 \mathrm{~h}$ ".

${ }^{\mathrm{b}} \mathrm{HR} 5 \mathrm{wt} \%$ Pd-doped MWCNTs denotes "as-synthesized surface-modified $5 \mathrm{wt} \%$ multiwalled carbon nanotubes reduced at $453 \mathrm{~K}$ under flowing hydrogen gas for $6 \mathrm{~h}$ ". 


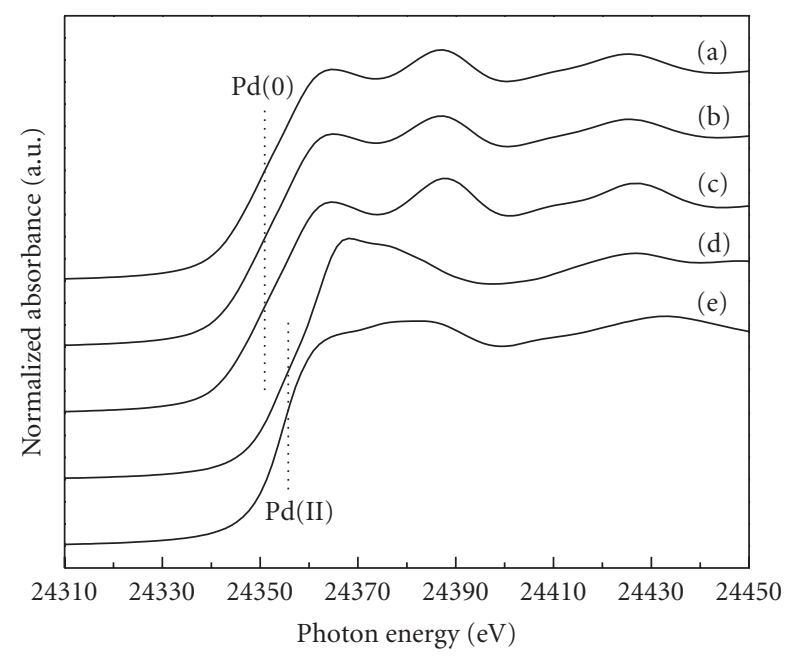

FIGURE 7: XANES spectra of (a) non-surface- and (b) surfacemodified $5 \mathrm{wt} \%$ Pd-doped MWCNTs after $\mathrm{H}_{2}$ reduction at $433 \mathrm{~K}$ for $6 \mathrm{~h},(\mathrm{c}) \mathrm{Pd},(\mathrm{d}) \mathrm{PdO}$, and (e) $\mathrm{PdCl}_{2}$ powder standards.

The intensive peak of the $\operatorname{Pd}(0) \mathrm{K}$-edge region around $24,368 \mathrm{eV}$ and the stronger $24,392 \mathrm{eV}$ quantify the transition metals of Pd on the surface of MWCNTs and occurred due to the orbital $3 \mathrm{~d} \rightarrow 5 \mathrm{~s}$ or $4 \mathrm{p}$ hybridization caused by unoccupied $d$ bands as shown in Figures 7 (a)-7(e) $[53,56,64]$. Therefore, the absorption was intensive at $3 d \rightarrow 5 s$ or $4 p$ hybridization. The p-like density of states was notably enhanced and the absorption could increase like the second absorption peak in the XANES spectra of the Pd standards (Figure 7(a)). In addition, compared with the absorption cross section of the Pd standard, it might be extensively increased because of the $3 d \rightarrow 4 p$ hybridization of $\mathrm{Pd}(\mathrm{II})[8,53,56]$. By using the EXAFS spectra shown in Figure 8 , the Pd clusters possessed a Pd-Pd bond distance of $2.76 \pm 0.05 \AA$ with a coordination number around 9 and the $\mathrm{PdCl}_{2}$ species had a $\mathrm{Pd}-\mathrm{Cl}$ bond distance of $2.25 \pm 0.05 \AA$ with a coordination number of $2[53,64]$. In the EXAFS data analyzed, the Debye-Waller factors $\left(\Delta \sigma^{2}\right)$ were less than $0.015\left(\AA^{2}\right)$ indicating that the center $\mathrm{Pd}$ atoms were the coordinated by $\mathrm{Pd}-\mathrm{Pd}$ bonding confirmatively. The apparent shortening of the bond distance with coordination number probably was caused by the random motion of surface atoms on the small Pd particles and that posed to increase the surface area of the Pd-doped MWCNT samples. Furthermore, this result also revealed that the Pd nanoparticles were well dispersed on the surface of the MWCNTs, which improved the amount of hydrogen storage efficiency significantly.

The unique adsorptive properties of carbon nanotubes suggest enormous potential applications for the fuel cell power generation systems. Laboratory-scale experiments were carried out to provide information concerning the feasibility for $\mathrm{H}_{2}$ storage ability of MWCNTs, and to determine if further developments would be warranted. The chemical modification of MWCNTs surfaces was done for the hydrogen adsorption capacity enhancement using a concentrated solution of $\mathrm{H}_{2} \mathrm{SO}_{4} / \mathrm{HNO}_{3}$ method. In order to know more detail about the hydrogen adsorption behavior

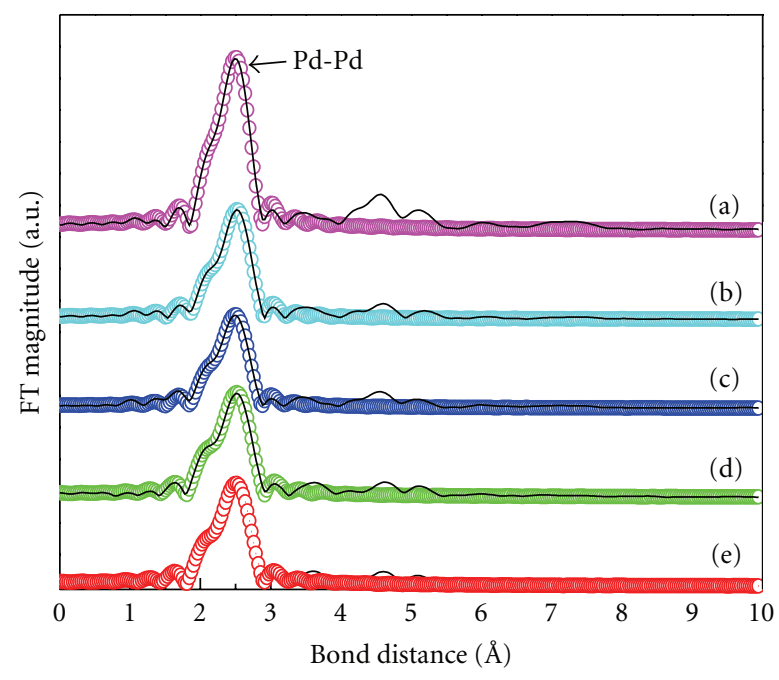

FIgURE 8: Fourier transform (FT) spectra of (a) Pd powder standard, (b) non-surface-modified $5 \mathrm{wt} \%$ Pd-doped MWCNTs after $\mathrm{H}_{2}$ reduction at $433 \mathrm{~K}$ for $6 \mathrm{~h}$, (c) fresh non-surface-modified $5 \mathrm{wt} \%$ Pd-doped MWCNTs, (d) surface-modified $5 \mathrm{wt} \%$ Pd-doped MWCNTs after $\mathrm{H}_{2}$ reduction at $433 \mathrm{~K}$ for $6 \mathrm{~h}$, and (e) fresh surfacemodified $5 \mathrm{wt} \%$ Pd-doped MWCNTs. The best fitting of the EXAFS spectra are expressed by the circle lines.



Figure 9: Hydrogen adsorption curves of (a) $4 \mathrm{wt} \% \mathrm{Ti}-\mathrm{NaAlH}_{4}+$ $5 \mathrm{wt} \%$ MWCNTs (at $425 \mathrm{~K}$ ), (b) $\mathrm{NaAlH}_{4}+5 \mathrm{wt} \%$ MWCNTs (at $425 \mathrm{~K}$ ), (c) $5 \mathrm{wt} \% \mathrm{Pd}$-doped MWCNTs (at $298 \mathrm{~K}$ ), and (d) MWCNTs (at $298 \mathrm{~K}$ ). The adsorption pressures of as-synthesized hydrogen storage materials of MWCNTs were ranged of 1-30 atm.

and the efficiency of Pd-doped MWCNTs, the hydrogen adsorption was carried out and represented in Figure 9. The fine particle size and the crystalline structure of the Pd-doped MWCNTs are responsible for higher sorption of $\mathrm{H}_{2}$ as shown in Figure 9(c), compared with the as-synthesized MWCNTs without metal doping shown in Figure 9(d). In addition, antidispersive force and the expected specific interaction with Pd sites also played an important role in case of the Pddoped MWCNTs [46, 53]. The addition of Pd or Ti-NaAlH nanoparticles increased the amount of hydrogen adsorption on the surface of MWCNTs. 
The hydrogen storage capacity of MWCNTs improved by doping of $\mathrm{Pd}$ or $\mathrm{Ti}^{-\mathrm{NaAlH}_{4}}$ of about 2.7-3.8 wt\% measured at $30 \mathrm{~atm}$ and 298 to $425 \mathrm{~K}$ which makes it more feasible to apply into the fuel cell power generation system [46, 53]. Experimentally, the hydrogen adsorption selectivity of $\mathrm{Pd}$ or $\mathrm{Ti}-\mathrm{NaAlH}_{4}$-doped MWCNTs was increased due to the dispersion of the $\mathrm{Pd}$ or $\mathrm{Ti}_{-} \mathrm{NaAlH}_{4}$ nanomaterial, respectively. The surface roughness and abundance of metallic dispersion on the MWCNTs surface helped to increase the hydrogen adsorption performance. This result was also followed through the EXAFS analysis that surface atoms of the Pd nanoparticles exhibited random motion and posed to enhance the hydrogen adsorption behavior.

\section{Conclusions}

The potential synthesis route of MWCNTs with catalytic hexachlorobenzene in the presence of $\mathrm{Co} / \mathrm{Ni}$ catalyst precursors at $503-623 \mathrm{~K}$ for $12 \mathrm{~h}$ was investigated. The identified characteristics of as-synthesized or metallic doped MWCNTs as well as $\mathrm{H}_{2}$ storage capacity for the fuel cell application were also studied. TEM micrographs show that the MWCNTs have a bamboo-like structure with an average length of 1$500 \mathrm{~nm}$. The inner and outer diameters of MWCNTs were 20 and $45 \mathrm{~nm}$ in average, respectively. The XRD patterns indicated that the abstraction of $\mathrm{Cl}$ from hexachlorobenzene and the formation of the $\mathrm{KCl}$ precipitate were involved in the early stage of the synthesis process of MWCNTs. XANES spectra showed that the $\mathrm{Co} / \mathrm{Ni}$ catalyst precursors of the MWCNTs were all metallic Co or Ni species. Furthermore, the EXAFS spectra of $\mathrm{Co} / \mathrm{Ni}$ precursor residues revealed that the metallic Co or $\mathrm{Ni}$ nanoparticles have a central Co (or $\mathrm{Ni}$ ) atom with a coordination number of $2.92 \pm 0.05$ (or $5.96 \pm 0.05)$ and with a Co-Co bond distance of $2.49 \pm 0.05 \AA$ (or $2.48 \pm 0.05 \AA$ ). In addition, $\mathrm{Pd}$ or $\mathrm{PdCl}_{2}$ possessed a $\mathrm{Pd}-\mathrm{Pd}$ or $\mathrm{Pd}-\mathrm{Cl}$ bond distance as 2.76 or $2.25 \AA$ with a coordination number of around 9 or 2 , respectively. The capacity of $\mathrm{H}_{2}$ storage of the MWCNTs improved by $\mathrm{Pd}$ or $\mathrm{Ti}-\mathrm{NaAlH}_{4}$ was ranged of $2.7-3.8 \mathrm{wt} \%$. This result revealed that the $\mathrm{Ti}-\mathrm{NaAlH}_{4}$-dopant or $\mathrm{Pd}$ nanoparticles were well dispersed on MWCNTs and that improved the $\mathrm{H}_{2}$ storage capacity significantly. Moreover, surface-modified or Pdand $\mathrm{Ti}-\mathrm{NaAlH}_{4}$-doped MWCNTs are some of the potential hydrogen adsorption materials. The safe storage of high purity hydrogen fed to the proton exchange membrane fuel cells (PEMFC) stack for power generation makes surfacemodified MWCNTs utilization systems economically and environmentally attractive.

\section{Acknowledgment}

The financial support of the National Science Council (Contract no. NSC-95-2621-Z-155-002) of Taiwan, is gratefully acknowledged.

\section{References}

[1] S. Iijima, "Helical microtubules of graphitic carbon," Nature, vol. 354, no. 6348, pp. 56-58, 1991.
[2] M. S. Dresselhaus, G. Dresselhaus, and R. Saito, "Physics of carbon nanotubes," Carbon, vol. 33, no. 7, pp. 883-891, 1995.

[3] A. C. Dillon, K. M. Jones, T. A. Bekkedahl, C. H. Kiang, D. S. Bethune, and M. J. Heben, "Storage of hydrogen in singlewalled carbon nanotubes," Nature, vol. 386, no. 6623, pp. 377379, 1997.

[4] J. Hone, M. Whitney, and A. Zettl, "Thermal conductivity of single-walled carbon nanotubes," Synthetic Metals, vol. 103, no. 1-3, pp. 2498-2499, 1999.

[5] Y. Tong, C. Liu, P. X. Hou, H. M. Cheng, N. S. Xu, and J. Chen, "Field emission from aligned multi-walled carbon nanotubes," Physica B, vol. 323, no. 1-4, pp. 156-157, 2002.

[6] T. Guo, P. Nikolaev, A. Thess, D. T. Colbert, and R. E. Smalley, "Catalytic growth of single-walled manotubes by laser vaporization," Chemical Physics Letters, vol. 243, no. 1-2, pp. 49-54, 1995.

[7] Y. Jiang, Y. Wu, S. Zhang et al., "A catalytic-assembly solvothermal route to multiwall carbon nanotubes at a moderate temperature," Journal of the American Chemical Society, vol. 122, no. 49, pp. 12383-12384, 2000.

[8] Y. P. Sun, K. Fu, Y. Lin, and W. Huang, "Functionalized carbon nanotubes: properties and applications," Accounts of Chemical Research, vol. 35, no. 12, pp. 1096-1104, 2002.

[9] X. Wang, J. Lu, Y. Xie, G. Du, Q. Guo, and S. Zhang, "A novel route to multiwalled carbon nanotubes and carbon nanorods at low temperature," Journal of Physical Chemistry B, vol. 106, no. 5, pp. 933-937, 2002.

[10] J. Liu, M. Shao, X. Chen, W. Yu, X. Liu, and Y. Qian, "Largescale synthesis of carbon nanotubes by an ethanol thermal reduction process," Journal of the American Chemical Society, vol. 125, no. 27, pp. 8088-8089, 2003.

[11] J. Liu, M. Shao, Q. Xie, L. Kong, W. Yu, and Y. Qian, "Singlesource precursor route to carbon nanotubes at mild temperature," Carbon, vol. 41, no. 11, pp. 2101-2104, 2003.

[12] A. Reyhani, S. Z. Mortazavi, A. Z. Moshfegh, A. N. Golikand, and M. Amiri, "Enhanced electrochemical hydrogen storage by catalytic Fe-doped multi-walled carbon nanotubes synthesized by thermal chemical vapor deposition," Journal of Power Sources, vol. 188, no. 2, pp. 404-410, 2009.

[13] J. Chen, M. A. Hamon, H. Hu et al., "Solution properties of single-walled carbon nanotubes," Science, vol. 282, no. 5386, pp. 95-98, 1998.

[14] S. S. Wong, A. T. Woolley, E. Joselevich, C. L. Cheung, and C. M. Lieber, "Covalently-functionalized single-walled carbon nanotube probe tips for chemical force microscopy," Journal of the American Chemical Society, vol. 120, no. 33, pp. 8557-8558, 1998.

[15] M. A. Hamon, H. Hu, P. Bhowmik et al., "End-group and defect analysis of soluble single-walled carbon nanotubes," Chemical Physics Letters, vol. 347, no. 1-3, pp. 8-12, 2001.

[16] J. Zhang, H. Zou, Q. Qing et al., "Effect of chemical oxidation on the structure of single-walled carbon nanotubes," Journal of Physical Chemistry B, vol. 107, no. 16, pp. 3712-3718, 2003.

[17] C. Branca, F. Frusteri, V. Magazù, and A. Mangione, "Characterization of carbon nanotubes by TEM and infrared spectroscopy," Journal of Physical Chemistry B, vol. 108, no. 11, pp. 3469-3473, 2004.

[18] Y. Xing, L. Li, C. C. Chusuei, and R. V. Hull, "Sonochemical oxidation of multiwalled carbon nanotubes," Langmuir, vol. 21, no. 9, pp. 4185-4190, 2005.

[19] A. Ansón, E. Lafuente, E. Urriolabeitia et al., "Preparation of palladium loaded carbon nanotubes and activated carbons for hydrogen sorption," Journal of Alloys and Compounds, vol. 436, no. 1-2, pp. 294-297, 2007. 
[20] S. Kocabas, T. Kopac, G. Dogu, and T. Dogu, "Effect of thermal treatments and palladium loading on hydrogen sorption characteristics of single-walled carbon nanotubes," International Journal of Hydrogen Energy, vol. 33, no. 6, pp. 1693-1699, 2008.

[21] O. Gülseren, T. Yildirim, and S. Ciraci, "Tunable adsorption on carbon nanotubes," Physical Review Letters, vol. 87, no. 11, Article ID 116802, pp. 116802/1-116802/4, 2001.

[22] Y. Wang, W. Deng, X. Liu, and X. Wang, "Electrochemical hydrogen storage properties of ball-milled multi-wall carbon nanotubes," International Journal of Hydrogen Energy, vol. 34, no. 3, pp. 1437-1443, 2009.

[23] J. Moc, D. G. Musaev, and K. Morokuma, "Activation and adsorption of multiple $\mathrm{H}_{2}$ molecules on a Pd5 cluster: a density functional study," Journal of Physical Chemistry A, vol. 107, no. 24, pp. 4929-4939, 2003.

[24] D. J. Ross, M. D. Halls, A. G. Nazri, and R. F. Aroca, "Raman scattering of complex sodium aluminum hydride for hydrogen storage," Chemical Physics Letters, vol. 388, no. 4-6, pp. 430435, 2004.

[25] P. Wang and C. M. Jensen, "Preparation of Ti-doped sodium aluminum hydride from mechanical milling of NaH/AI with off-the-shelf Ti powder," Journal of Physical Chemistry B, vol. 108, no. 40, pp. 15827-15829, 2004.

[26] S. Chaudhuri and J. T. Muckerman, "First-principles study of Ti-catalyzed hydrogen chemisorption on an Al surface: a critical first step for reversible hydrogen storage in $\mathrm{NaAlH}_{4}$," Journal of Physical Chemistry B, vol. 109, no. 15, pp. 69526957, 2005.

[27] E. H. Majzoub, J. L. Herberg, R. Stumpf, S. Spangler, and R. S. Maxwell, "XRD and NMR investigation of Ti-compound formation in solution-doping of sodium aluminum hydrides: Solubility of Ti in $\mathrm{NaAlH}_{4}$ crystals grown in THF," Journal of Alloys and Compounds, vol. 394, no. 1-2, pp. 265-270, 2005.

[28] J. Wang, A. D. Ebner, T. Prozorov, R. Zidan, and J. A. Ritter, "Effect of graphite as a co-dopant on the dehydrogenation and hydrogenation kinetics of Ti-doped sodium aluminum hydride," Journal of Alloys and Compounds, vol. 395, no. 1-2, pp. 252-262, 2005.

[29] J. Wang, A. D. Ebner, R. Zidan, and J. A. Ritter, "Synergistic effects of co-dopants on the dehydrogenation kinetics of sodium aluminum hydride," Journal of Alloys and Compounds, vol. 391, no. 1-2, pp. 245-255, 2005.

[30] V. J. Surya, K. Iyakutti, M. Rajarajeswari, and Y. Kawazoe, "Functionalization of single-walled carbon nanotube with borane for hydrogen storage," Physica E, vol. 41, no. 7, pp. 1340-1346, 2009.

[31] D. Pukazhselvan, B. K. Gupta, A. Srivastava, and O. N. Srivastava, "Investigations on hydrogen storage behavior of CNT doped $\mathrm{NaAlH}_{4}$," Journal of Alloys and Compounds, vol. 403, no. 1-2, pp. 312-317, 2005.

[32] P. A. Berseth, A. G. Harter, R. Zidan et al., "Carbon nanomaterials as catalysts for hydrogen uptake and release in NaAIH4," Nano Letters, vol. 9, no. 4, pp. 1501-1505, 2009.

[33] C. Liu, Y. Chen, C. Z. Wu, S. T. Xu, and H. M. Cheng, "Hydrogen storage in carbon nanotubes revisited," Carbon, vol. 48, no. 2, pp. 452-455, 2010.

[34] D. Lin and B. Xing, "Tannic acid adsorption and its role for stabilizing carbon nanotube suspensions," Environmental Science and Technology, vol. 42, no. 16, pp. 5917-5923, 2008.

[35] Z. T. Liu, C. X. Wang, Z. W. Liu, and J. Lu, "Selective hydrogenation of cinnamaldehyde over Pt-supported multi-walled carbon nanotubes: insights into the tube-size effects," Applied Catalysis A, vol. 344, no. 1-2, pp. 114-123, 2008.
[36] A. Lueking and R. T. Yang, "Hydrogen spillover from a metal oxide catalyst onto carbon nanotubes-implications for hydrogen storage," Journal of Catalysis, vol. 206, no. 1, pp. 165$168,2002$.

[37] G. Gundiah, A. Govindaraj, N. Rajalakshmi, K. S. Dhathathreyan, and C. N. R. Rao, "Hydrogen storage in carbon nanotubes and related materials," Journal of Materials Chemistry, vol. 13, no. 2, pp. 209-213, 2003.

[38] E. Yoo, L. Gao, T. Komatsu et al., "Atomic hydrogen storage in carbon nanotubes promoted by metal catalysts," Journal of Physical Chemistry B, vol. 108, no. 49, pp. 18903-18907, 2004.

[39] S. Dag, Y. Ozturk, S. Ciraci, and T. Yildirim, "Adsorption and dissociation of hydrogen molecules on bare and functionalized carbon nanotubes," Physical Review B, vol. 72, no. 15, pp. 155404-155411, 2005.

[40] A. Lan and A. Mukasyan, "Hydrogen storage capacity characterization of carbon nanotubes by a microgravimetrical approach," Journal of Physical Chemistry B, vol. 109, no. 33, pp. 16011-16016, 2005.

[41] A. Ansón, E. Lafuente, E. Urriolabeitia et al., "Hydrogen capacity of palladium-loaded carbon materials," Journal of Physical Chemistry B, vol. 110, no. 13, pp. 6643-6648, 2006.

[42] F. H. Yang, A. J. Lachawiec, and R. T. Yang, "Adsorption of spillover hydrogen atoms on single-wall carbon nanotubes," Journal of Physical Chemistry B, vol. 110, no. 12, pp. 62366244, 2006.

[43] V. Gayathri and R. Geetha, "Hydrogen adsorption in defected carbon nanotubes," Adsorption, vol. 13, no. 1, pp. 53-59, 2007.

[44] C. T. Hsieh, Y. W. Chou, and J. Y. Lin, "Fabrication and electrochemical activity of Ni-attached carbon nanotube electrodes for hydrogen storage in alkali electrolyte," International Journal of Hydrogen Energy, vol. 32, no. 15, pp. 3457-3464, 2007.

[45] M. K. Kumar and S. Ramaprabhu, "Palladium dispersed multiwalled carbon nanotube based hydrogen sensor for fuel cell applications," International Journal of Hydrogen Energy, vol. 32, no. 13, pp. 2518-2526, 2007.

[46] S. U. Rather, R. Zacharia, S. W. Hwang, M. U. D. Naik, and K. S. Nahm, "Hydrogen uptake of palladium-embedded MWCNTs produced by impregnation and condensed phase reduction method," Chemical Physics Letters, vol. 441, no. 46, pp. 261-267, 2007.

[47] R. Zacharia, S. U. Rather, S. W. Hwang, and K. S. Nahm, "Spillover of physisorbed hydrogen from sputter-deposited arrays of platinum nanoparticles to multi-walled carbon nanotubes," Chemical Physics Letters, vol. 434, no. 4-6, pp. 286-291, 2007.

[48] K. M. Brieño-Enriquez, J. Ledesma-García, J. J. Perez-Bueno, L. A. Godinez, H. Terrones, and C. Ángeles-Chavez, "Bonding titanium on multi-walled carbon nanotubes for hydrogen storage: an electrochemical approach," Materials Chemistry and Physics, vol. 115, no. 2-3, pp. 521-525, 2009.

[49] K. Iyakutti, Y. Kawazoe, M. Rajarajeswari, and V. J. Surya, "Aluminum hydride coated single-walled carbon nanotube as a hydrogen storage medium," International Journal of Hydrogen Energy, vol. 34, no. 1, pp. 370-375, 2009.

[50] W. Liu, Y. H. Zhao, Y. Li, Q. Jiang, and E. J. Lavernia, "Enhanced hydrogen storage on li-dispersed carbon nanotubes," Journal of Physical Chemistry C, vol. 113, no. 5, pp. 2028-2033, 2009.

[51] S. U. Rather, N. Mehraj-ud-din, R. Zacharia, S. W. Hwang, A. R. Kim, and K. S. Nahm, "Hydrogen storage of nanostructured $\mathrm{TiO}_{2}$-impregnated carbon nanotubes," International Journal of Hydrogen Energy, vol. 34, no. 2, pp. 961-966, 2009. 
[52] R. Zacharia, K. Y. Kim, A. K. M. Fazle Kibria, and K. S. Nahm, "Enhancement of hydrogen storage capacity of carbon nanotubes via spill-over from vanadium and palladium nanoparticles," Chemical Physics Letters, vol. 412, no. 4-6, pp. 369375, 2005.

[53] Y. Suttisawat, P. Rangsunvigit, B. Kitiyanan et al., "Investigation of hydrogen storage capacity of multi-walled carbon nanotubes deposited with Pd or V," International Journal of Hydrogen Energy, vol. 34, no. 16, pp. 6669-6675, 2009.

[54] J. Wang, A. D. Ebner, and J. A. Ritter, "Kinetic behavior of Ti-doped $\mathrm{NaAlH}_{4}$ when cocatalyzed with carbon nanostructures," Journal of Physical Chemistry B, vol. 110, no. 35, pp. 17353-17358, 2006.

[55] T. Yildirim and S. Ciraci, "Titanium-decorated carbon nanotubes as a potential high-capacity hydrogen storage medium," Physical Review Letters, vol. 94, no. 17, Article ID 175501, pp. 175501-175504, 2005.

[56] S. D. Conradson, "Application of X-ray absorption fine structure spectroscopy to materials and environmental science," Applied Spectroscopy, vol. 52, no. 7, pp. 252A-279A, 1998.

[57] G. Vlaic, D. Andreatta, and P. E. Colavita, "Characterisation of heterogeneous catalysts by EXAFS," Catalysis Today, vol. 41, no. 1-3, pp. 261-275, 1998.

[58] D. Koningsberger, B. Mojet, J. Miller, and D. Ramaker, "XAFS spectroscopy in catalysis research: AXAFS and shape resonances," Journal of Synchrotron Radiation, vol. 6, no. 3, pp. 135-141, 1999.

[59] H. Li, M. Eddaoudi, M. O’Keeffe, and O. M. Yaghi, “Design and synthesis of an exceptionally stable and highly porous metal- organic framework," Nature, vol. 402, no. 6759, pp. 276-279, 1999.

[60] X. Li, H. Zhu, C. Xu, Z. Mao, and D. Wu, "Measuring hydrogen storage capacity of carbon nanotubes by tangentmass method," International Journal of Hydrogen Energy, vol. 28, no. 11, pp. 1251-1253, 2003.

[61] H. Z. Geng, T. H. Kim, S. C. Lim et al., "Hydrogen storage in microwave-treated multi-walled carbon nanotubes," International Journal of Hydrogen Energy, vol. 35, no. 5, pp. 2073 2082, 2010.

[62] F. W. Lytle, "The EXAFS family tree: a personal history of the development of extended X-ray absorption fine structure," Journal of Synchrotron Radiation, vol. 6, no. 3, pp. 123-134, 1999.

[63] B. Bogdanović and M. Schwickardi, "Ti-doped $\mathrm{NaAlH}_{4}$ as a hydrogen-storage material-preparation by Ti-catalyzed hydrogenation of aluminum powder in conjunction with sodium hydride," Applied Physics A, vol. 72, no. 2, pp. 221223, 2001.

[64] S. D. Lin, Y. H. Hsu, P. H. Jen, and J. F. Lee, "Probing Pdcarbon interaction in $\mathrm{Pd} / \mathrm{C}$ catalysts by EXAFS," Journal of Molecular Catalysis A, vol. 238, no. 1-2, pp. 88-95, 2005. 

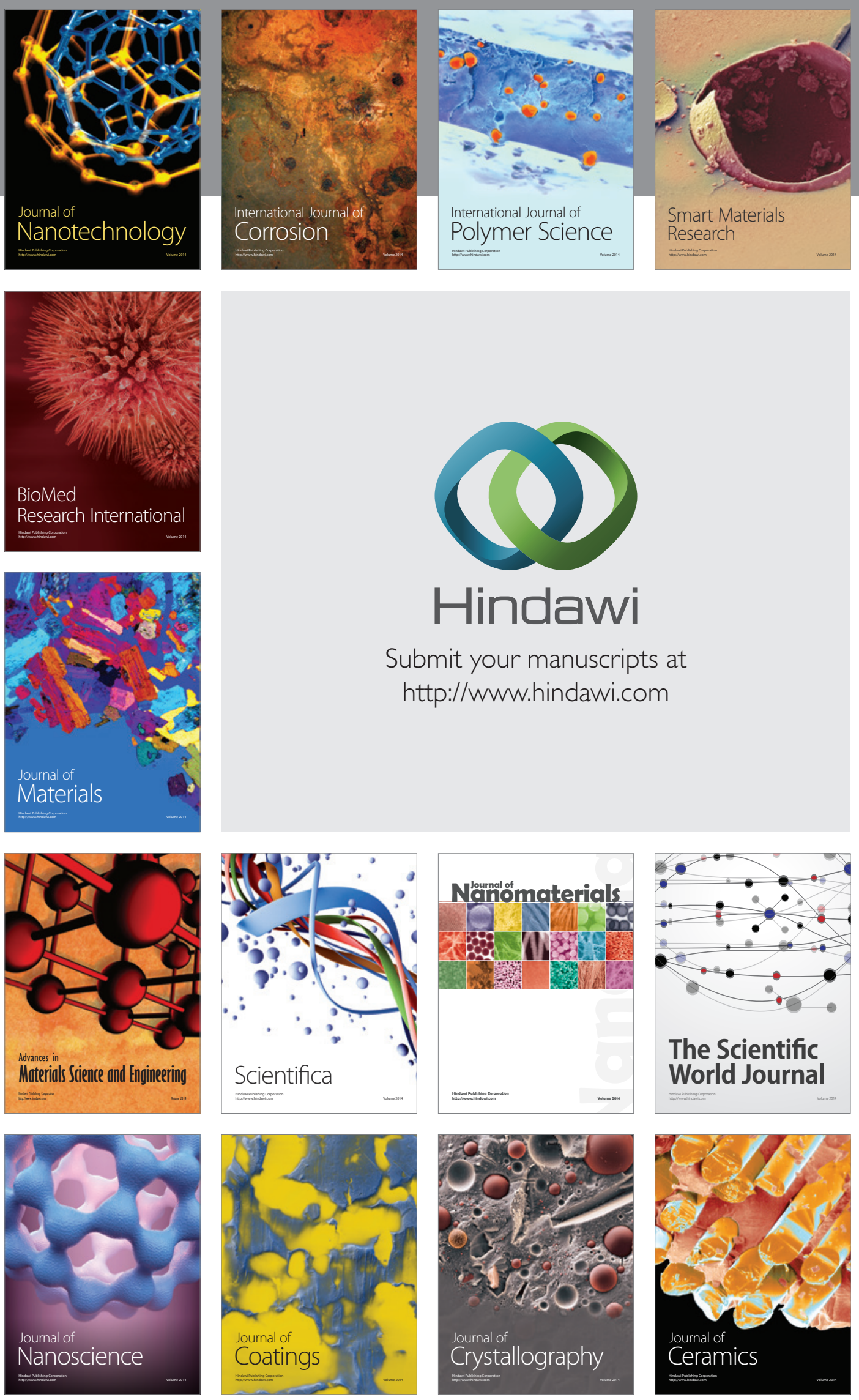

The Scientific World Journal

Submit your manuscripts at

http://www.hindawi.com

\section{World Journal}

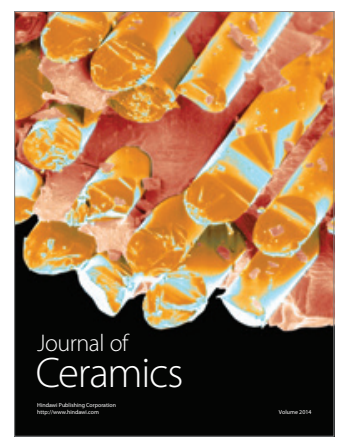

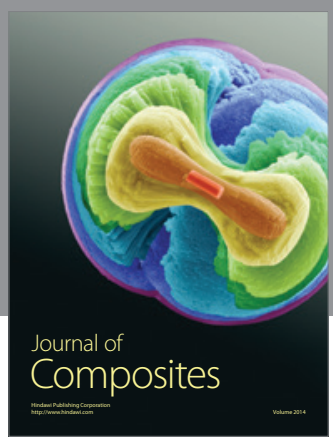
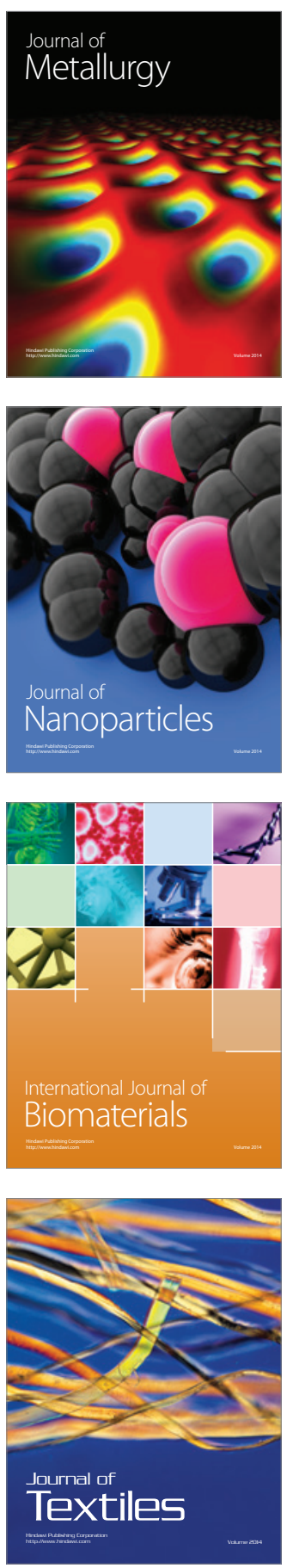